\title{
La obra de Banksy: arte urbano o callejero como medio de reivindicación histórico, social, cultural y político
}

\author{
Beatriz Garrido-Ramos | Universidad de Educación a Distancia (UNED) \\ URL de la contribución <www.iaph.es/revistaph/index.php/revistaph/article/view/4895>
}

El arte urbano o callejero (traducción de la expresión inglesa street art que hace referencia al arte de la calle, frecuentemente ilegal), el grafiti y el muralismo se han convertido sin duda, desde hace décadas, en una verdadera forma de expresión artística así como de reivindicación social que no puede pasarse por alto. Se trata de obras que se realizan en el entorno urbano, podríamos decir para la recuperación del espacio público urbano (Aracil 2019).

Característico de este tipo de arte es Banksy, seudónimo de un prolífico artista del street art británico del que se desconoce prácticamente toda su biografía. Inició sus pasos en este mundo sirviéndose de él como medio de expresión personal. Utiliza su arte urbano callejero para promover visiones distintas a las de los grandes medios de comunicación, invitando así a la reflexión social, política y cultural.

Por lo que respecta a la intención política que subyace de su obra, esta puede estar influida por los llamados Ad Jammers, movimiento que deformaba las imágenes de los anuncios publicitarios para cambiar el mensaje (Hermoso-Espinosa 2007).

En la obra de este artista la crítica ocupa un lugar importante. Buen ejemplo de ello es The Banksy Luxury Loft Complex, obra en la que se puede observar una escena de violencia ejercida sobre animales, tema reivindicativo por el que desde hace tiempo se está luchando a nivel mundial.

Otro ejemplo de carácter reivindicativo es el mural que realizó sobre el Muro de Cisjordania -combinando varias técnicas- en agosto de 2005. También podríamos citar Girl with Balloon (South Park, Londres, 2002),
Guantanamo Bay Prisoner (2007), Stop and Search (Palestina, 2007), Shop until You Drop (2011), Thinker (Gaza, 2014), etc.

Pero la obra que más recientemente ha suscitado polémica y que se ha atribuido al conocido pero a la vez desconocido artista ha sido la del muro de la prisión Reading, en Berkshire, Reino Unido, en la que fue encarcelado en su día el mismísimo Oscar Wilde.

A pesar de que el artista todavía no se haya pronunciado al respecto en cuanto a la autoría de la que podría ser hasta la fecha su última obra, rápidamente le fue atribuida, tanto por las características de la misma como, probablemente, por la falta de reconocimiento por parte de otro u otra artista. Esta atribución de la obra a Banksy nos conduce a pensar en la existencia de una serie de signos identificativos (trazos, elementos comunes, etc.) que permiten relacionar este tipo de obras urbanas con sus respectivos autores o autoras, a pesar de que no se identifiquen explícitamente, como en el caso que nos ocupa. Socialmente, el trabajo ya ha sido atribuido y clasificado, y esto es posible porque el artista ha calado profundamente en la ciudadanía.

El mural del muro de la prisión Reading implica en sí mismo una reivindicación histórica y cultural, puesto que contribuye al mantenimiento del patrimonio histórico (material-el propio edificio- o inmaterial -la historia del personaje relevante que en ella estuvo y a cuya memoria parece podría dedicarse la obra-) y la memoria colectiva. $Y$ es que se presume que la obra ha sido realizada como una muestra de apoyo por parte del artista a la campaña lanzada para salvar el histórico edificio de la prisión después de que fuera clausurado en el año 2014. 


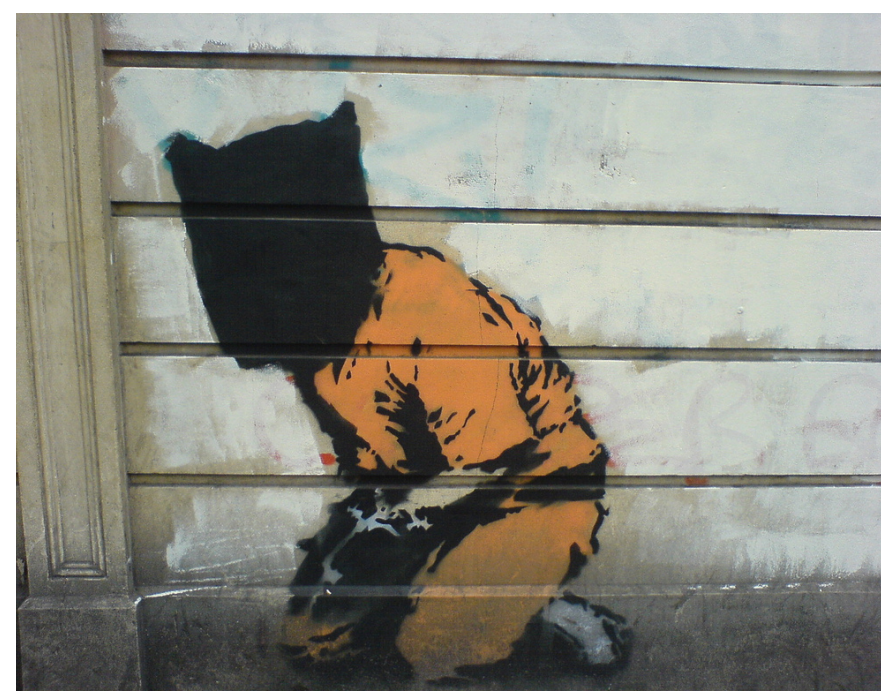

Guantanamo Bay Prisoner | foto eadmundo

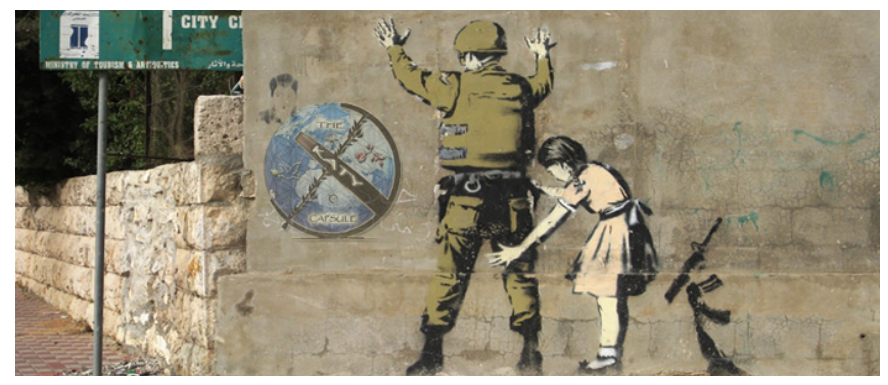

Stop and search | foto Wall in Palestine

Pero además, el arte callejero, al integrar sus elementos en lugares públicos bastante transitados (como sucede por ejemplo con los carteles publicitarios), sin duda tiene un fin concreto: pretende sorprender a los espectadores y viandantes, a lo que añadiríamos que probablemente también busca sentar las bases para un debate social sobre temas de actualidad o que, como mínimo, preocupan e inquietan, con los que, en consecuencia, se puede relacionar sus obras.

Banksy suele emplear en su discurso un mensaje subversivo llamativo, mediante el cual critica con ironía e invita a la lucha social, a la crítica política o, simplemente, a la reflexión. Se ha hablado incluso de este tipo de arte como posible terapia social, pudiendo prevenir el vandalismo entre los más jóvenes, tal y como afirmó en

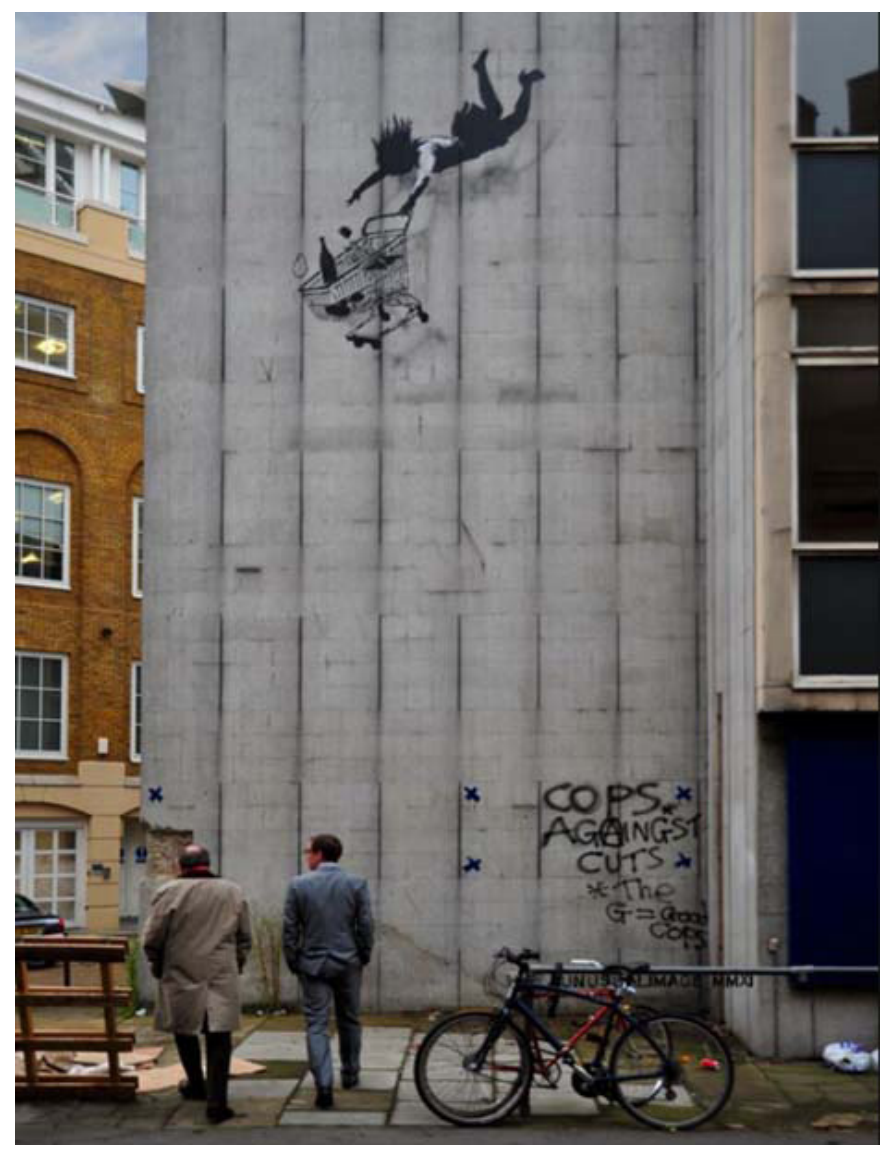

Shop till you drop | foto Lou Gold

su día el educador social Antoni Gabarre (2013), que ha trabajado en lugares tan dispares como Bosnia e Irlanda del Norte así como en cárceles, siempre en lugares con problemas de integración.

En definitiva concluimos que las obras y murales urbanos como los de este artista, además de poder considerarse patrimonio cultural en sí mismo y apostar por su conservación, realizan una importante labor, contribuyendo a la recuperación de la memoria histórica y a la reivindicación social, a pesar de que para ello se recurra al, en ocasiones, tan denostado y maltratado arte del grafiti. 


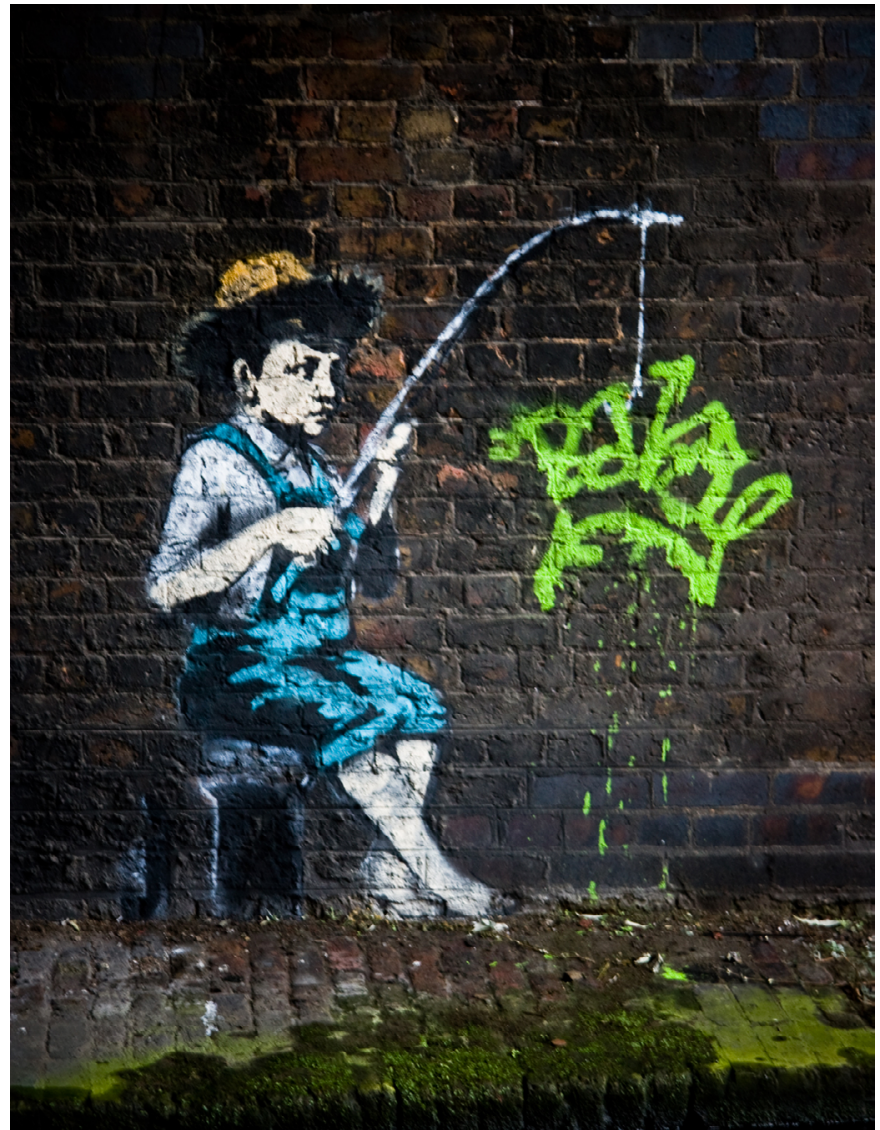

Banksy. Candem Town, Londres | foto Dan H

\section{BIBLIOGRAFÍA}

- Aracil, E. (2019) Desmontando a Banksy. Un análisis de su técnica y de su obra. Disponible en: https://www. desmontandoabanksy.es/analisis-obra-mensaje/43/analisisobra-banksy [Consulta: 06/04/2021]

- Aznar, Y. y Reyes, J. (2010) Últimas Tendencias del Arte. Madrid: Ed. Ramón Areces

- Banksy. Web de Banksy (2021) Disponible en: https:// banksy.co.uk/ [Consulta: 06/04/2021]

- El arte urbano como terapia, objetivo de la exposición que Antoni Gabarre muestra en La Rábida. Huelva noticias, 4 de diciembre de 2013. Disponible en: https://huelvabuenasnoticias. com/2013/12/04/el-arte-urbano-como-terapia-objetivo-dela-exposicion-que-antoni-gabarre-muestra-en-la-rabida/ [Consulta: 04/04/2014]

- Galtung, J. (2003) Tras la violencia, 3R: reconstrucción, reconciliación, resolución. Afrontando los efectos visibles e invisibles de la guerra y la violencia. Gernika, Bakeaz: Gernika Gogoratuz

- Garrido-Ramos, B. (2014) Reflejo de la violencia en el mundo actual a través del Arte. ArtyHum Revista Digital de Artes y Humanidades, n. ${ }^{\circ}$ 5, pp. 48-56. Disponible en: https://www. artyhum.com/descargas/PDF/ArtyHum\%20n\%C2\%BA\%2005. pdf\#page=49 [Consulta: 06/04/2021]

- Hermoso-Espinosa, S. (2007) Banksy, el Arte del grafiti. Homines.com, 22 de noviembre de 2007. Disponible en: https://www.homines.com/arte_xx/banksy/index.htm [Consulta: 06/04/2021]

- Una posible obra de Banksy aparece en el muro de la prisión donde fue encarcelad Oscar Wilde. Público, 2 de marzo de 2021. Disponible en: https://www.publico.es/photonews/ banksy-posible-obra-banksy-aparece-muro-prisionencarcelado-oscar-wilde.html [Consulta: 04/03/2021] 